\title{
Efficacy of novel antibacterial compounds targeting histidine kinase YycG protein
}

\author{
Huayong Liu • Dan Zhao • Jun Chang • Liang Yan • \\ Fuju Zhao • Youcong Wu • Tao Xu • Ting Gong • \\ Li Chen • Nianan He $\cdot$ Yang Wu $\cdot$ Shiqing Han $\cdot$ Di Qu
}

Received: 16 December 2013 /Revised: 9 March 2014 / Accepted: 11 March 2014 /Published online: 17 April 2014

(C) The Author(s) 2014. This article is published with open access at Springerlink.com

\begin{abstract}
Treating staphylococcal biofilm-associated infections is challenging. Based on the findings that compound 2 targeting the HK domain of Staphylococcus epidermidis YycG has bactericidal and antibiofilm activities against staphylococci, six newly synthesized derivatives were evaluated for their antibacterial activities. The six derivatives of compound 2 inhibited autophosphorylation of recombinant $\mathrm{YycG}^{\prime}$ and the $\mathrm{IC}_{50}$ values ranged from 24.2 to $71.2 \mu \mathrm{M}$. The derivatives displayed bactericidal activity against planktonic S. epidermidis or Staphylococcus aureus strains in the MIC
\end{abstract}

Huayong Liu and Dan Zhao contributed equally to this work.

Electronic supplementary material The online version of this article (doi:10.1007/s00253-014-5685-8) contains supplementary material, which is available to authorized users.

H. Liu $\cdot$ L. Yan • Y. Wu • T. Xu • T. Gong • L. Chen • Y. Wu ( $\bowtie) \cdot$ D. Qu $(\bowtie)$

Key Laboratory of Medical Molecular Virology of Ministries of Education and Health, School of Basic Medical Science and Institutes of Biomedical Sciences, Shanghai Medical College of Fudan University, Shanghai 200032, China

e-mail: yangwu@fudan.edu.cn

e-mail: dqu@fudan.edu.cn

D. Zhao $\cdot$ S. Han $(\bowtie)$

College of Biotechnology and Pharmaceutical Engineering,

Nanjing University of Technology, Nanjing 210009, China

e-mail: hanshiqing@njut.edu.cn

F. Zhao

Department of Clinical Laboratory, Huadong Hospital,

Fudan University, Shanghai, China

J. Chang

Department of Natural Products Chemistry, School of Pharmacy, Fudan University, Shanghai, China

N. He

Department of Ultrasound, Anhui Provincial Hospital of Anhui Medical University, Hefei 230001, China range of $1.5-3.1 \mu \mathrm{M}$. All the derivatives had antibiofilm activities against the 6- and 24-h biofilms of $S$. epidermidis. Compared to the prototype compound 2, they had less cytotoxicity for Vero cells and less hemolytic activity for human erythrocytes. The derivatives showed antibacterial activities against clinical methicillin-resistant staphylococcal isolates. The structural modification of YycG inhibitors will assist the discovery of novel agents to eliminate biofilm infections and multidrug-resistant staphylococcal infections.

Keywords Staphylococcus epidermidis $\cdot$ Methicillin-resistant Staphylococcus aureus (MRSA) · Antibacterial · Minimal inhibitory concentration (MIC) $\cdot$ Minimal bactericidal concentration $(\mathrm{MBC}) \cdot$ Antibiofilm activity

\section{Introduction}

Staphylococcus epidermidis and Staphylococcus aureus are common pathogens in medical device biofilm-associated infections (Knobloch et al. 2001; Yarwood et al. 2004). Their ability to attach onto biomaterial surfaces of implanted medical devices or to fragments of dead tissue and form biofilms results in chronic and refractory infections (Otto 2012b) that are resistant to antibiotics and to host defense clearance mechanisms (Spoering and Lewis 2001). S. epidermidis is a common cause of biofilm-associated infections, even though it is less virulent than S. aureus (Giacometti et al. 2000; O'Gara and Humphreys 2001). Biofilm-associated infections persist until the implanted medical device is removed, resulting in extra trauma and cost (Donlan and Costerton 2002; Kiran et al. 2010). Up to $25 \%$ of orthopedic implants are subject to revision surgery due to biofilm infections (Mah and O'Toole 2001; Otto 2012a).

Currently available antibiotics for the treatment of bacterial infections are targeted at the planktonic cells, not the sessile 
cells in biofilms (Falsetta et al. 2012). Consequently, strategies against staphylococcal biofilm infections include targeting the systems regulating biofilm formation, such as two-component systems or quorum sensing systems; degrading the matrix to disperse the bacteria; developing a new generation of antibiotics; and adopting novel combinations of antimicrobial agents (West and Stock 2001; Yarwood et al. 2004). However, the mechanisms of multiple antibiotic resistance in S. epidermidis and S. aureus biofilms are complex. The biofilm matrix may decrease antibiotic diffusion into the biofilm structure, causing the bacteria to have less exposure to the antimicrobial compounds. Nutrient or oxygen depletion within the biofilm causes the cells to have low metabolic activity and a reduced growth rate, thus rendering biofilm bacteria resistant to antibiotics (Aendekerk et al. 2005; Walters et al. 2003). Most existing antibiotics fail to adequately penetrate the biofilm or have limited activity against surface-attached cells and cells with low metabolic activity (Kiedrowski and Horswill 2011). Vancomycin is regarded as an antibiotic of last resort against methicillin-resistant $S$. aureus (MRSA), methicillin-resistant S. epidermidis (MRSE), and other multiple antibiotic-resistant infections caused by gram-positive bacteria, but it has no significant effect on the bacteria in a biofilm (Qin et al. 2006; Roper et al. 2000). Daptomycin and linezolid are now available for biofilm-associated infections caused by staphylococci, but neither was found to be bactericidal against biofilm-embedded bacteria (Parra-Ruiz et al. 2012). More novel drugs are urgently required to combat staphylococcal biofilm-associated infections and the targeting of a bacterial two-component system (TCS) is the approach taken here.

A TCS, composed of a histidine kinase (HK) and a response regulator (RR), serves as a basic stimulus-response coupling mechanism by which bacteria sense and respond to environmental changes. TCSs have been found in bacteria, fungi, and plants, but not in vertebrates (Barrett and Hoch 1998; West and Stock 2001). YycFG is an essential TCS that is highly conserved in gram-positive bacteria with a low $\mathrm{G}+\mathrm{C}$ content (Dubrac et al. 2007). It plays important roles in the growth, cell wall metabolism, and biofilm formation of pathogenic staphylococcal species (Winkler and Hoch 2008). It has been suggested that $\mathrm{YycG}$ or $\mathrm{YycF}$ may serve as potential targets for the development of novel antimicrobial agents (Fukushima et al. 2011; Szurmant et al. 2005; Turck and Bierbaum 2012).

We have previously described two YycG inhibitors that target the HK domain of $S$. epidermidis $\mathrm{YycG}$ and show bactericidal and antibiofilm activities against $S$. epidermidis and $S$. aureus. One of the two leading compounds is compound 2: $\{2-\{4-\{3-(2-$ ethylphenyl)-2-[(2-ethylphenyl)imino]-4oxothiazolidin-5-ylidene $\}$ methyl $\}$-2-methoxyphenoxy $\}$ acetic acid (Huang et al. 2012; Qin et al. 2006). To enhance the antimicrobial activities of compound 2 and reduce the toxicity to mammalian cells, the structure was optimized in a series of derivatives by substituting different functional groups (fluorine group, thiophene ring, etc.) while keeping the core structure intact (Dan Zhao et al. 2013). Six out of 56 newly synthesized derivatives of compound 2 were selected for their antiStaphylococcus activity. In this study, we evaluated the antimicrobial activities of the six derivatives, including in vitro minimal inhibitory concentration (MIC), bactericidal activity, antibiofilm efficacy, YycG phosphorylation-inhibiting activity, potential toxicity, and in vivo effectiveness in a rabbit subcutaneous $S$. epidermidis biofilm infection model.

\section{Materials and methods}

Ethics statement

All procedures performed on rabbits were conducted according to relevant national and international guidelines (the Regulations for the Administration of Affairs Concerning Experimental Animals, China) and were approved by the Institutional Animal Care and Use Committee (IACUC) of Shanghai Medical College, Fudan University (IACUC Animal Project Number: 20110630).

Bacterial strains, media, and derivatives of compound 2

Bacterial strains S. epidermidis ATCC 12228 (nonbiofilm forming), S. epidermidis ATCC 35984 (biofilm forming), S. aureus ATCC 49230, and S. aureus ATCC 25923 were from the American Type Culture Collection (ATCC, Manassas, USA) and were cultured in tryptic soy broth medium (TSB; Oxoid Ltd., Basingstoke, England). Ten clinical methicillinresistant staphylococcal isolates, five MRSA isolates and five MRSE isolates, were collected from Huadong Teaching Hospital in Shanghai. Escherichia coli ATCC 25922 was grown in Luria-Bertani (LB) broth. The six compounds used in this study (H2-38, H2-39, H2-57, H2-60, H2-74, and H2-81) were screened from 56 derivatives of compound 2 in which the functional groups were modified, but the thiazolidine core structure was unchanged. The compounds were synthesized by Nanjing University of Technology. To generate the derivative compounds, halogen atoms were introduced into 4thiazolidinone compounds that contained carboxylic acid moieties of phenoxy-acetic acid, (5-vinyl-furan-2-yl)-benzoic acid or (5-vinyl-thiophene-2-yl)-benzoic acid. The derivatives were dissolved in dimethyl sulfoxide (DMSO; Amresco, USA) to $200 \mathrm{mM}$ for use as stock solutions. The structures and systematic names of the derivatives are listed in Fig. 1.

\section{MIC and MBC assays}

MICs of the derivatives for S. epidermidis and S. aureus were determined by the broth dilution method according to the 


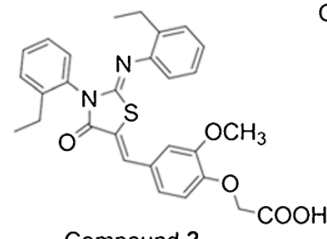

Compound 2
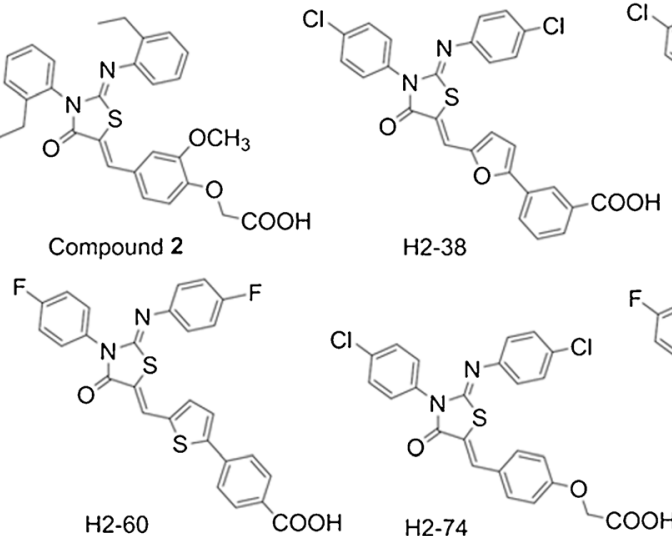

$\mathrm{H} 2-38$
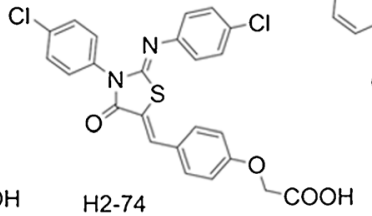

Fig. 1 The structures of the thiazolidione derivatives. Based on the thiazolidione core structure of compound $2\{2-\{4-\{3-(2-$ ethylphenyl)2-[(2-ethylphenyl)imino]-4-oxothiazolidin-5-ylidene methyl\}-2methoxyphenoxy acetic acid, six derivatives were designed and synthesized by modifying the functional groups through cyclization, aldol condensation, substitution and hydrolyzation reactions. H2-38,

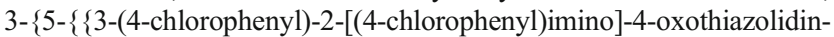
5-ylidene $\}$ methyl $\}$ furan-2-yl $\}$ benzoic acid; H2-39, 4- $\{5-\{\{3-(4-$ chlorophenyl)-2-[(4-chlorophenyl)imino]-4-oxothiazolidin-5-

National Committee for Clinical Laboratory (NCCLS) recommendations (Turnidge and Bordash 2007). Twofold dilutions of the derivatives in tubes containing $4 \mathrm{ml}$ of Mueller-Hinton broth (MH, Sigma, Germany) were made to concentrations from 200 to $0.39 \mu \mathrm{M}$. Overnight cultures of the bacteria were adjusted to the $0.5 \mathrm{McF}$ arland standards and inoculated 1:200 into the $\mathrm{MH}$ broth and then incubated at $37{ }^{\circ} \mathrm{C}$ for $16-20 \mathrm{~h}$. The lowest concentration inhibiting visible growth of the bacteria was recorded as minimal inhibitory concentration (MIC). For the minimal bactericidal concentration (MBC) assay, a $100-\mu 1$ aliquot from the MIC assay tubes with no visible turbidity was spread on freshly prepared $\mathrm{MH}$ agar plates and incubated at $37^{\circ} \mathrm{C}$ for $24 \mathrm{~h}$, and the colonies were counted. The MBC of the derivatives was determined as the lowest concentration of the derivative required to allow less than five colonies to grow on each plate (Qin et al. 2006).

\section{Inhibition of $Y_{y c G}$ autophosphorylation}

Recombinant YycG (YycG', amino acids 370-610) was prepared by expressing the HATPase_c and HisKA domains of $\mathrm{YycG}$ in E. coli BL21 (DE3). In brief, the sequence coding for $\mathrm{YycG}^{\prime}$ was amplified from the genome of S. epidermidis ATCC 35984 by PCR and cloned into the pET28a (+) vector, which inserts a GB1 tag (B1 domain of protein $\mathrm{G}, 56$ residues) to make the recombinant fusion protein highly soluble and stable. The recombinant $\mathrm{YycG}^{\prime}$ ylidene $\}$ methyl $\}$ furan-2-yl $\}$ benzoic acid; H2-57, 4- $\{5-\{\{3-(4-$ chlorophenyl)-2-[(4-phenyl)imino]-4-oxothiazolidin-5ylidene $\}$ methyl $\}$ furan-2-yl $\}$ benzoic acid; H2-60, 4- $\{5-\{\{3-(4-$ fluorophenyl)-2-[(4-fluorophenyl)imino]-4-oxothiazolidin-5ylidene $\}$ methyl $\}$ thiophene-2-yl $\}$ benzoic acid; H2-74, 2-\{4-\{[3-(4chlorophenyl)-2-[(4-chlorophenyl)imino]-4-oxothiazolidin-5ylidene $\}$ methyl $\}$ phenoxy $\}$ acetic acid; H2-81, 4- $\{5-\{\{3-(4-$ fluorophenyl)-2-[(4-phenyl)imino]-4-oxothiazolidin-5ylidene\} methyl\}thiophene-2-yl benzoic acid

protein was fused to the GB1 tag at its N-terminus end, expressed in E. coli BL21 (DE3) and purified by $\mathrm{Ni}^{2+}$ affinity chromatography on a Ni-NTA column (Qiagen, Germany). The purified $\mathrm{YycG}^{\prime}$ was cleaved by TEV protease and further purified by Ni-NTA and Superdex 75 gel filtration columns (GE Healthcare, USA).

The Kinase-Glo ${ }^{\mathrm{TM}}$ Luminescent Kinase Assay (Promega, Madison, WI, USA) was used to measure the inhibitory activities of the derivatives against the autophosphorylation activity of the recombinant $Y_{y c G}$ following the manufacturer's recommendation. The derivatives were serially diluted from 200 to $1.6 \mu \mathrm{M}$ with reaction buffer $(40 \mathrm{mM}$ Tris $\mathrm{pH} 8.0$, $20 \mathrm{mM} \mathrm{MgCl}$, and $0.1 \mathrm{mg} / \mathrm{ml} \mathrm{BSA}$ ). Recombinant YycG' $(0.02 \mu \mathrm{g} / \mu \mathrm{l})$ and diluted derivative were added into a 96-well plate and incubated at $25^{\circ} \mathrm{C}$ for $30 \mathrm{~min}$, and then $4 \mu \mathrm{M}$ ATP was added into each well and incubated for another $30 \mathrm{~min}$. Finally, $50 \mu \mathrm{l} \mathrm{Kinase-Glo}{ }^{\mathrm{TM}}$ Reagent containing luciferase (kinase) and D-luciferin was added. The luminescent signal generated by luciferase was in proportion to the amount of ATP remaining in the reaction. Luminescence was detected by a Perkin Elmer Victor X5 luminescence plate reader, and the intensity was recorded as relative light units (RLU). The wells containing ATP and Kinase-Glo ${ }^{\mathrm{TM}}$ without $\mathrm{YycG}^{\prime}$ and derivatives or containing $\mathrm{YycG}^{\prime}$ plus ATP and Kinase-Glo ${ }^{\mathrm{TM}}$ without the derivatives were used as the controls. The percentage inhibition of protein phosphorylation $(\mathrm{Rp})$ by the derivatives was calculated as follows:

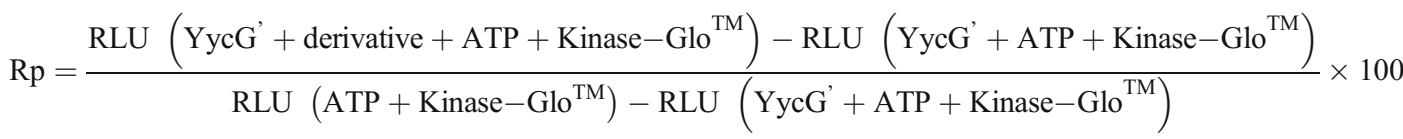


The concentration of a derivative required to inhibit half of the autophosphorylation of recombinant $\mathrm{YycG}^{\prime}$ (half maximal inhibitory concentration, $\mathrm{IC}_{50}$ ) was calculated with Origin 8.0 software (Origin Lab, Northampton, USA). Three independent assays were carried out, and each was performed in quadruplicate.

\section{Microtiter plate assay of S. epidermidis biofilms}

The effects of the derivatives on immature (6-h-old) biofilms and mature (24-h-old) biofilms of S. epidermidis ATCC 35984 were detected by using a semiquantitative microtiter plate assay (Stepanovic et al. 2007). An overnight culture of bacteria was inoculated 1:200 into TSB medium containing $0.25 \%$ glucose and statically incubated in a polystyrene $96-$ well plate $\left(200 \mu \mathrm{l}\right.$ per well) at $37{ }^{\circ} \mathrm{C}$ for 6 or $24 \mathrm{~h}$. The medium containing any nonadherent bacteria was then removed, and serial dilutions of derivatives in $200 \mu \mathrm{l}$ fresh TSB were added to the wells and incubated for another $16 \mathrm{~h}$ at $37^{\circ} \mathrm{C}$. The wells were then washed gently three times with phosphate buffered saline (PBS), air-dried, fixed with methanol, and stained with $2 \%(w / v)$ crystal violet. The staining was visually assessed and scanned at $570 \mathrm{~nm}$ using a 96-well plate spectrophotometer (DTX880, Beckman Coulter, USA), and the minimal biofilm eradication concentration (MBEC) was measured (Ceri et al. 1999).

Observation of S. epidermidis biofilms by confocal laser scanning microscopy

The effects of the derivatives on bacterial viability in mature (24-h-old) biofilms of S. epidermidis ATCC 35984 were evaluated by a confocal laser scanning microscope (CLSM), with Live/Dead staining (BacLight, Molecular Probes, USA) for assessing bacterial viability (Qin et al. 2006). A diluted overnight culture of the bacteria was inoculated into cell culture glass bottom dishes (WPI, USA) and incubated at $37{ }^{\circ} \mathrm{C}$ for $24 \mathrm{~h}$. After removal of the suspension cultures, the derivatives in fresh TSB at fourfold MIC concentration were added and incubated at $37^{\circ} \mathrm{C}$ for $16 \mathrm{~h}$. The biofilms were washed with PBS and stained with SYTO9 and propidium iodide (PI), both of which were used at a concentration of $1 \mu \mathrm{M}$. SYTO9stained live cells and PI-stained cells dead in biofilms were visualized by a Leica TCS SP5 confocal laser scanning microscope with a $\times 631.4$-NA oil immersion objective. Threedimensional biofilm images were created by IMARIS 7.0.0 software (Bitplane).

Observation of S. epidermidis biofilms by scanning electron microscopy

S. epidermidis ATCC 35984 was statically incubated for $6 \mathrm{~h}$ in polystyrene 96 -well plates at $37{ }^{\circ} \mathrm{C}$, then the diluted derivatives $\mathrm{H} 2-74$ and $\mathrm{H} 2-81$ were added at concentrations of $4 \times$ MIC in fresh TSB medium and incubated for another $16 \mathrm{~h}$ at $37^{\circ} \mathrm{C}$. After the incubation, the wells were washed with PBS, fixed with glutaraldehyde (2.5\% in PBS) for $2 \mathrm{~h}$, and rinsed with PBS. All samples were mounted on SEM sample stubs, sputtered with platinum, and observed under a field emission scanning electron microscope (JSM-6700 F, Japan).

\section{Kinetics of killing planktonic S. epidermidis}

An overnight culture of S. epidermidis ATCC 35984 was inoculated into $20 \mathrm{ml}$ of fresh $\mathrm{MH}$ broth at a 1:200 dilution $\left(10^{6} \mathrm{CFU} / \mathrm{ml}\right)$. Concentrations of $\mathrm{H} 2-74$ or $\mathrm{H} 2-81$ from $0.38 \mu \mathrm{M}(1 / 4 \times \mathrm{MIC})$ to $6.3 \mu \mathrm{M}(4 \times \mathrm{MIC})$ were added and incubated at $37{ }^{\circ} \mathrm{C}$ with shaking at $200 \mathrm{rpm}$ for $12 \mathrm{~h}$. Every $2 \mathrm{~h}, 100 \mu \mathrm{l}$ of the culture was diluted and spread on agar plates. Viable bacteria $(\mathrm{CFU})$ were counted and the rate and extent of killing were determined by plotting $\mathrm{CFU} / \mathrm{ml}$ against time (D'Arezzo et al. 2012; Lee et al. 2008). This experiment was independently repeated three times.

Cytotoxicity and hemolytic activity of the derivatives

Vero 76 cells (African green monkey cells) were used to determine the cytotoxicity of the derivatives with the Cell Proliferation Kit I (MTT) (Roche, Indianapolis, USA). The Vero cells were grown in Dulbecco's modified Eagle's medium (DMEM), supplemented with $5 \%$ fetal calf serum, 100 $\mathrm{U} / \mathrm{ml}$ penicillin, $100 \mathrm{mg} / \mathrm{ml}$ streptomycin, and $2 \mathrm{mML}$-glutamine. After culturing in $5 \% \mathrm{CO}_{2}$ at $37{ }^{\circ} \mathrm{C}$ for $48 \mathrm{~h}$, the cells were harvested and dispensed into 96-well cell culture plates containing $5 \times 10^{4}$ cells per well in $100 \mu l$. The cells were coincubated with serial twofold dilutions of derivatives from 200 to $6.25 \mu \mathrm{M}$ (six different concentrations) for $24 \mathrm{~h}$ at $37^{\circ} \mathrm{C}$ in $5 \% \mathrm{CO}_{2}$. Then, $10 \mu \mathrm{l}$ of the MTT labeling reagent (final concentration $0.5 \mathrm{mg} / \mathrm{ml}$ ) was added to each well and incubated for $4 \mathrm{~h}$. The solubilization solution $(100 \mu \mathrm{l}$ per well) was added to dissolve the purple formazan salts generated in the viable cells, and the absorbance of each well was measured at $595 \mathrm{~nm}$. Cells treated with the solvent $(0.1 \%$ DMSO) were used as a negative control and the cells cultured only with DMEM medium served as a blank control. The inhibitory rate was calculated as follows:

Inhibitory rate $\%=\frac{\text { Ocontrol-ODtest }}{\text { ODcontrol }} \times 100$

$\mathrm{CC}_{50}$ was defined as the concentration of the derivatives that inhibited the Vero cell growth by $50 \%$ and was calculated with the Origin v8.0 software (Origin Lab, Northampton, USA) (Qin et al. 2006). 
The hemolytic activities of the derivatives on healthy human erythrocytes were also determined. Healthy human erythrocytes resuspended in normal saline (NS) at $5 \%(v / v)$ were co-incubated with the derivatives at final concentrations of MIC, $4 \times \mathrm{MIC}$, or $200 \mu \mathrm{M}$ for $1 \mathrm{~h}$ at $37{ }^{\circ} \mathrm{C}$ in 96 well microtiter plates. The suspensions were centrifuged at $350 \mathrm{~g}$ for $10 \mathrm{~min}$ and the supernatant $(100 \mu \mathrm{l})$ was transferred to new wells and measured at $570 \mathrm{~nm}$ on a spectrophotometer (Benchmark Microplate Reader; Bio-Rad, Hercules, CA, USA). The percentage of hemolysis was calculated by normalizing against the absorbance of erythrocytes treated with $1 \%$ Triton X-100, which caused complete hemolysis; $0.1 \%$ DMSO-treated cells were used as a control (Miyoshi et al. 1997). The experiment was performed in quadruplicate wells and repeated independently three times.

Rabbit subcutaneous $S$. epidermidis biofilm infection model

To test the effectiveness in vivo of H2-74 and H2-81, 24-h biofilms of $S$. epidermidis grown on polyethylene disks were imbedded subcutaneously into the New Zealand White rabbits and treated with the derivatives for $72 \mathrm{~h}$ in a modification of the method used previously (He et al. 2011). Disks were cut from polyethylene 96 -well plates $(8 \mathrm{~mm}$ diameter, $1 \mathrm{~mm}$ thickness), sterilized with $75 \%$ ethanol and placed in a Petri dish (100 mm diameter). An overnight culture of S. epidermidis ATCC $35984(20 \mathrm{ml})$ was inoculated into the dish and incubated at $37{ }^{\circ} \mathrm{C}$ for $24 \mathrm{~h}$. The disks covered with biofilms were then implanted subcutaneously in female New Zealand White rabbits $(2.0-2.5 \mathrm{~kg})$ that had been anesthetized with pentobarbital sodium ( $5 \mathrm{mg} / \mathrm{kg}$ i.v.). Four incisions $(10 \mathrm{~mm})$ were made on the back of the rabbit along the spine bilaterally after removal of fur, and the sub cutis was carefully dissected to form a $2-\mathrm{cm} \times 3-\mathrm{cm}$ cavity. Two biofilm-covered polyethylene disks were implanted into each cavity, and to minimize the effect of between-animal variation, four different treatments were given locally to each rabbit.

The treatments were as follows: $1 \mathrm{ml}$ of $\mathrm{H} 2-74(6.3 \mu \mathrm{M}$, $4 \times \mathrm{MIC})$ or $\mathrm{H} 2-81(6.3 \mu \mathrm{M}, 4 \times \mathrm{MIC})$ dissolved in NS was injected into the cavity locally after the biofilm-covered disks were implanted and the incisions were sutured, and the same dosages were administered at 24 and $48 \mathrm{~h}$. Vancomycin $(128 \mathrm{mg} / \mathrm{l})$ and $0.1 \%$ DMSO were administered as the controls. Twenty-four hours after the last treatment, the rabbits were euthanized and the implants were taken out with sterile forceps. Biofilms were scraped from the disks, and the viable bacteria were determined by CFU counting, as previously described (He et al. 2011). All animals were housed and used in compliance with the guidelines of the Institute of Animal Care and Use Committee, and the protocol was approved by the committee.
Statistical analysis

Data from the rabbit model of S. epidermidis biofilm infection were compared by one-way analysis of variance (ANOVA) and Bonferroni's multiple comparison test using the Origin v8.0 software (Origin Lab, Northampton, USA). A $p$ value less than 0.05 was considered statistically significant.

\section{Results}

Six of our 56 synthesized derivatives of leading compound 2 (H2-38, H2-39, H2-57, H2-60, H2-74, and H2-81) had exhibited low MICs $(\leq 3.1 \mu \mathrm{M})$ against S. epidermidis ATCC 35984 (Huang et al. 2012; Qin et al. 2006) and were selected for further investigation of antimicrobial and antibiofilm activities.

\section{Inhibition of $\mathrm{YycG}^{\prime}$ autophosphorylation}

The inhibition effects of the six derivatives on the autophosphorylation activity of the purified recombinant $\mathrm{YycG}^{\prime}$ were detected by using the Kinase-Glo ${ }^{\mathrm{TM}}$ Luminescent Kinase Assay. The recombinant YycG' hydrolyzed ATP for its autophosphorylation in the reaction; the phosphorylation of $\mathrm{YycG}^{\prime}$ was inhibited when treated with the derivatives and the $\mathrm{IC}_{50}$ values of each derivatives were calculated. At a concentration of $100 \mu \mathrm{M}, \mathrm{H} 2-38, \mathrm{H} 2-39, \mathrm{H} 2-57, \mathrm{H} 2-60, \mathrm{H} 2-74$, and H2-81 inhibited the enzymatic autophosphorylation of $\mathrm{YycG}^{\prime}$ $(0.13 \mu \mathrm{M})$ by $61.8,56.3,59.7,55.4,53.9$, and $79.2 \%$, respectively. The $\mathrm{IC}_{50}$ values of the six derivatives ranged from 24.2 to $71.2 \mu \mathrm{M}$ and the $\mathrm{IC}_{50}$ of the prototype compound 2 was $47.9 \mu \mathrm{M}$ as shown in Table 1.

\section{Antimicrobial activities of the derivatives}

All six derivatives inhibited the growth of $S$. epidermidis ATCC 35984 in MH broth; the MIC values of the derivatives ranged from 1.6 to $3.1 \mu \mathrm{M}$, and the $\mathrm{MBC}$ ranged from 6.3 to $25 \mu \mathrm{M}$, while the MIC and MBC of compound 2 were much higher which were 25 and $100 \mu \mathrm{M}$, respectively (Table 1). The ratios of MIC/MBC values of most derivatives (H2-38, $\mathrm{H} 2-39, \mathrm{H} 2-57, \mathrm{H} 2-60$, and $\mathrm{H} 2-81$ ) ranged from $1 / 2$ to $1 / 8$, whereas for $\mathrm{H} 2-74$, the ratio reached 1/16.

According to the different bacteriostatic and bactericidal activities of the derivatives, we chose $\mathrm{H} 2-74$ and $\mathrm{H} 2-81$ for further assay and tested killing kinetics against planktonic bacteria. In the initial treatment phase (from 2 to $6 \mathrm{~h}$ ), at the concentrations of $1 / 4 \mathrm{MIC}(0.38 \mu \mathrm{M})$ and $1 / 2 \mathrm{MIC}(0.75 \mu \mathrm{M})$, $\mathrm{H} 2-74$ and H2-81 inhibited the growth of $S$. epidermidis, as shown in Fig. 2. When treated with $\mathrm{H} 2-74$ at $2 \times \mathrm{MIC}(3.1 \mu \mathrm{M}$ for $12 \mathrm{~h}$, the viable cells were decreased to $3.2 \times 10^{3} \mathrm{CFU} / \mathrm{ml}$ (Fig. 2a), while with $\mathrm{H} 2-81$ treatment at $2 \times \mathrm{MIC}$, the viability 
Table 1 Biological activities of the six derivatives of compound 2

\begin{tabular}{|c|c|c|c|c|c|c|c|c|c|}
\hline \multirow[t]{2}{*}{ Derivatives $^{\text {a }}$} & \multirow[t]{2}{*}{ Molecular weight } & \multirow[t]{2}{*}{$\left.\mathbf{M I C}^{\mathrm{b}} \mu \mathbf{M}\right)$} & \multirow[t]{2}{*}{$\mathbf{M B C}(\mu \mathbf{M})$} & \multirow[t]{2}{*}{ MIC/MBC } & \multirow[t]{2}{*}{$\mathbf{M B E C}^{\mathbf{b}}(\mu \mathbf{M})$} & \multirow[t]{2}{*}{$\left.\mathrm{IC}_{50} \mathrm{c} \mu \mathrm{M}\right)$} & \multirow[t]{2}{*}{$\mathrm{CC}_{50}{ }^{\mathrm{d}} \cdot(\mu \mathrm{M})$} & \multicolumn{2}{|c|}{ Hemolysis $(\%)^{\mathbf{e}}$} \\
\hline & & & & & & & & At MIC & $200 \mu \mathbf{M}$ \\
\hline Compound 2 & 519 & 25 & 100.0 & $1 / 4$ & 100.0 & $47.9 \pm 5.3$ & 50 & $2.31 \pm 0.35$ & $5.24 \pm 0.21$ \\
\hline $\mathrm{H} 2-38$ & 534.02 & 1.5 & 12.5 & $1 / 8$ & 12.5 & $41.4 \pm 3.4$ & $>200$ & $0.14 \pm 0.03$ & $0.28 \pm 0.03$ \\
\hline H2-39 & 534.02 & 1.5 & 12.5 & $1 / 8$ & 12.5 & $59.8 \pm 1.4$ & $>200$ & $0.12 \pm 0.03$ & $0.41 \pm 0.05$ \\
\hline $\mathrm{H} 2-57$ & 500.06 & 3.1 & 12.5 & $1 / 4$ & 12.5 & $47.1 \pm 1.5$ & $>200$ & $0.14 \pm 0.03$ & $0.16 \pm 0.04$ \\
\hline $\mathrm{H} 2-60$ & 518.06 & 1.5 & 12.5 & $1 / 8$ & 12.5 & $63.7 \pm 2.3$ & $>200$ & $0.52 \pm 0.06$ & $0.84 \pm 0.03$ \\
\hline $\mathrm{H} 2-74$ & 498.02 & 1.5 & 25.0 & $1 / 16$ & 50.0 & $71.2 \pm 4.9$ & $>200$ & $0.14 \pm 0.03$ & $0.42 \pm 0.03$ \\
\hline $\mathrm{H} 2-81$ & 500.07 & 1.5 & 6.3 & $1 / 4$ & 6.3 & $24.2 \pm 1.2$ & $>200$ & $0.06 \pm 0.09$ & $0.10 \pm 0.03$ \\
\hline
\end{tabular}

${ }^{\text {a }}$ Stock solutions $(200 \mathrm{mM})$ of the derivatives were prepared in DMSO, and $200 \mu \mathrm{M}$ was the highest concentration used in this study

${ }^{\mathrm{b}} \mathrm{MIC}, \mathrm{MBC}$, and MBEC represent minimal inhibitory concentration, minimal bactericidal concentration, and minimal biofilm eradication concentration of the derivatives against $S$. epidermidis ATCC 35984

${ }^{\mathrm{c}} \mathrm{IC}_{50}$ represents half maximal inhibitory concentration of the derivatives, which is the concentration needed to inhibit half of the autophosphorylation of recombinant $\mathrm{YycG}^{\prime}$ determined by the Kinase-Glo ${ }^{\mathrm{TM}}$ Luminescent Kinase Assay kit

${ }^{\mathrm{d}} \mathrm{CC}_{50}$ represents the derivative concentration that produces $50 \%$ cytotoxicity effects on Vero cells. At $200 \mu \mathrm{M}$, cytotoxicity of the derivatives on the Vero cells was less than $3 \%$ determined by the MTT assay with the Cell Proliferation Kit

${ }^{\mathrm{e}}$ Hemolytic activities of the derivatives at the MICs and $200 \mu \mathrm{M}$ were detected on healthy human erythrocytes

was decreased to less than $3 \times 10^{2} \mathrm{CFU} / \mathrm{ml}$ (Fig. 2b). When treated with $\mathrm{H} 2-81$ at the concentration of $4 \times \mathrm{MIC}(6.3 \mu \mathrm{M})$ for $10 \mathrm{~h}$, the viable cells decreased to fewer than $10 \mathrm{CFU} / \mathrm{ml}$, but for $\mathrm{H} 2-74$, more than $3.1 \times 10^{2} \mathrm{CFU} / \mathrm{ml}$ were left.

We further tested the antimicrobial activity of the six derivatives on two $S$. aureus standard strains $(S$. aureus ATCC 49230 and S. aureus ATCC25923) and ten clinical methicillinresistant staphylococcal strains (five MRSE and five MRSA isolates). All six derivatives were able to inhibit the growth of $S$. aureus in addition to $S$. epidermidis, and the MIC values ranged from 1.6 to $6.3 \mu \mathrm{M}$ (Table 2). They had no effect on the growth of E. coli strain ATCC 25922 at $200 \mu \mathrm{M}$, which is the highest concentration used in the present study.

\section{Effect of the derivatives on $S$. epidermidis biofilms}

The activities of the six derivatives on the both immature and mature biofilms of $S$. epidermidis ATCC 35984 were

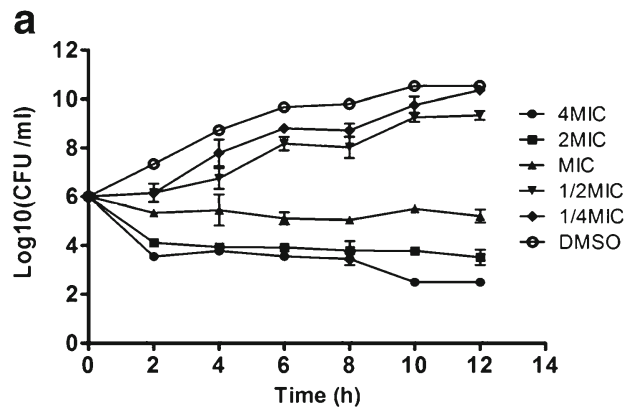

Fig. 2 The kinetics of H2-74 and H2-81 action against $S$. epidermidis ATCC 35984. The bacteria were cultured with H2-74 (a) or H2-81 (b) at $1 / 4 \times \mathrm{MIC}, 1 / 2 \times \mathrm{MIC}, 1 \times \mathrm{MIC}, 2 \times \mathrm{MIC}$, and $4 \times \mathrm{MIC}$ in $20 \mathrm{ml}$ of fresh $\mathrm{MH}$ broth, at $37^{\circ} \mathrm{C}$ for $12 \mathrm{~h}$. Every $2 \mathrm{~h}$, viable bacteria (CFU) were evaluated, and the MBEC was determined. When 6-h-old (immature) biofilms on 96-well plates were treated for $12 \mathrm{~h}$, the six derivatives all inhibited biofilm formation. The MBEC ranged from 6.3 to $50 \mu \mathrm{M}$, lower than that of compound 2; H2-81 had the lowest MBEC and H2-74 the highest (Table 2). When 24-h-old (mature) biofilms were treated, no difference was found between the $\mathrm{OD}_{570}$ values of the treated and untreated biofilms (data not shown).

When 6-h-old biofilms on the polystyrene bottomed plates were treated with either $\mathrm{H} 2-74$ or $\mathrm{H} 2-81$ at a concentration of $4 \times \mathrm{MIC}$, few bacteria on the plates were observed using scanning electron microscopy. When treated with vancomycin $(128 \mathrm{mg} / \mathrm{l})$, the morphology of the biofilms was similar to that treated with $0.1 \%$ DMSO as a negative control (Fig. 3).

When the bactericidal activity of the derivatives on mature (24-h-old) biofilms of S. epidermidis on glass was assessed by confocal microscopy with Live/Dead staining (CLSM), all six derivatives showed bactericidal activities at $4 \times$ MIC. $\mathrm{H} 2-81$

b

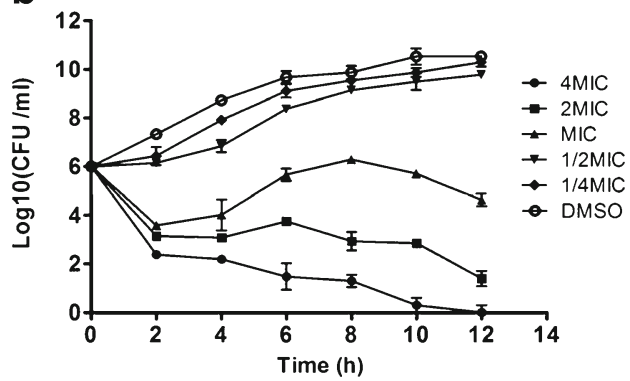

counted. The bacterial growth inhibition/killing was determined by plotting viable colony counts $(\mathrm{CFU} / \mathrm{ml})$ against time. The results are from three separate experiments and presented as the mean $\pm \mathrm{SD}$ of triplicate samples 
Table 2 Anti-Staphylococcus activities of the derivatives

${ }^{\text {a }} \mathrm{MIC}$, which represents minimal inhibitory concentration of the derivatives, was determined by the broth dilution (in tubes) method according to the standards of CLSI of the USA

${ }^{\mathrm{b}}$ The derivatives did not inhibit the growth of E. coli ATCC 25922 , even at the highest concentration used in the experiment ${ }^{\mathrm{c}}$ MIC values for compound 2 were determined in this study

\begin{tabular}{lllllll}
\hline Derivatives & \multicolumn{7}{l}{ MIC $^{\mathbf{a}}(\mu \mathrm{M})$} & \multicolumn{1}{c}{} & \\
\cline { 2 - 7 } & $\begin{array}{l}\text { S. epidermidis } \\
\text { ATCC 12228 }\end{array}$ & $\begin{array}{l}\text { S. aureus } \\
\text { ATCC } \\
\mathbf{4 9 2 3 0}\end{array}$ & $\begin{array}{l}\text { S. aureus } \\
\text { ATCC } \\
\mathbf{2 5 9 2 3}\end{array}$ & $\begin{array}{l}\text { Clinical MRSE } \\
\text { strains }(\boldsymbol{n}=\mathbf{5})\end{array}$ & $\begin{array}{l}\text { Clinical MRSA } \\
\text { strains }(\boldsymbol{n}=\mathbf{5})\end{array}$ & $\begin{array}{l}\boldsymbol{E} \text {. coli } \\
\text { ATCC } \\
\mathbf{2 5 9 2 2}^{\mathrm{b}}\end{array}$ \\
\hline Compound 2 & 25 & 50 & 50 & $25-50$ & $25-50$ & $>200$ \\
$\mathrm{H} 2-38$ & 1.5 & 1.5 & 1.5 & $1.5-3.1$ & $1.5-3.1$ & $>200$ \\
$\mathrm{H} 2-39$ & 1.5 & 1.5 & 1.5 & $1.5-3.1$ & $1.5-3.1$ & $>200$ \\
$\mathrm{H} 2-57$ & 3.1 & 1.5 & 3.1 & $1.5-3.1$ & $1.5-3.1$ & $>200$ \\
$\mathrm{H} 2-60$ & 1.5 & 1.5 & 1.5 & $1.5-3.1$ & $1.5-3.1$ & $>200$ \\
$\mathrm{H} 2-74$ & 1.5 & 1.5 & 3.1 & $3.1-6.3$ & $3.1-6.3$ & $>200$ \\
$\mathrm{H} 2-81$ & 1.5 & 1.5 & 1.5 & 1.5 & 1.5 & $>200$ \\
\hline
\end{tabular}

reduced the viability to $12.3 \%$, while $\mathrm{H} 2-60$ and $\mathrm{H} 2-57$ reduced viability to 14 and $17.1 \%$, respectively. The proportion of viable cells in the biofilms treated with vancomycin $(128 \mathrm{mg} / \mathrm{l})$ was $88.6 \%$, similar to that of $0.1 \%$ DMSO (Fig. 4).

Cytotoxicity and hemolytic activity of the derivatives

When the derivatives at six different concentrations up to $200 \mu \mathrm{M}$ were added onto Vero cells and incubated for $24 \mathrm{~h}$ at $37{ }^{\circ} \mathrm{C}$, the formation of formazan in the MTT viability assay was inhibited by less than $3 \%$. The $\mathrm{CC}_{50}$ values of all the derivatives were therefore greater than $200 \mu \mathrm{M}$ higher than that of the parent prototype compound $(50 \mu \mathrm{M}$ Cells treated with $0.1 \%$ DMSO showed no cytotoxicity (Table 1).

At the MIC concentrations, all six derivatives lysed healthy human erythrocytes by less than $1 \%$, while the prototype compound 2 produced $2.31 \pm 0.35 \%$ hemolysis (Table 2 ).
Even at the highest concentrations $(200 \mu \mathrm{M})$, all of the derivatives gave no obvious hemolysis, whereas compound 2 gave $5.24 \%$ hemolysis.

Antimicrobial efficacy of the derivatives in a rabbit subcutaneous S. epidermidis biofilm infection model

We evaluated antibiofilm activities of $\mathrm{H} 2-74$ and $\mathrm{H} 2-81$ in vivo using a rabbit subcutaneous $S$. epidermidis biofilm infection model. When 24-h-old biofilms of S. epidermidis on polyethylene disks were implanted subcutaneously and exposed for $72 \mathrm{~h}$ to either $\mathrm{H} 2-74$ or $\mathrm{H} 2-81$ at $4 \times \mathrm{MIC}$, bacterial viability was substantially reduced compared to DMSO or vancomycin controls (Fig. 5). CFUs in biofilms treated with $\mathrm{H} 2-74$ were reduced to $2.91 \pm 0.42 \log 10 \mathrm{CFU} / \mathrm{cm}^{2}$ and $\mathrm{H} 2-81$ to $2.18 \log 10 \mathrm{CFU} / \mathrm{cm}^{2}(p<0.05, n=6)$, whereas the CFUs in the $0.1 \%$ DMSO-treated biofilms were $5.3 \pm 0.15 \log 10 \mathrm{CFU} /$ $\mathrm{cm}^{2}$, and in the vancomycin-treated biofilms, 5.21 \pm 0.24 $\log 10 \mathrm{CFU} / \mathrm{cm}^{2}$.

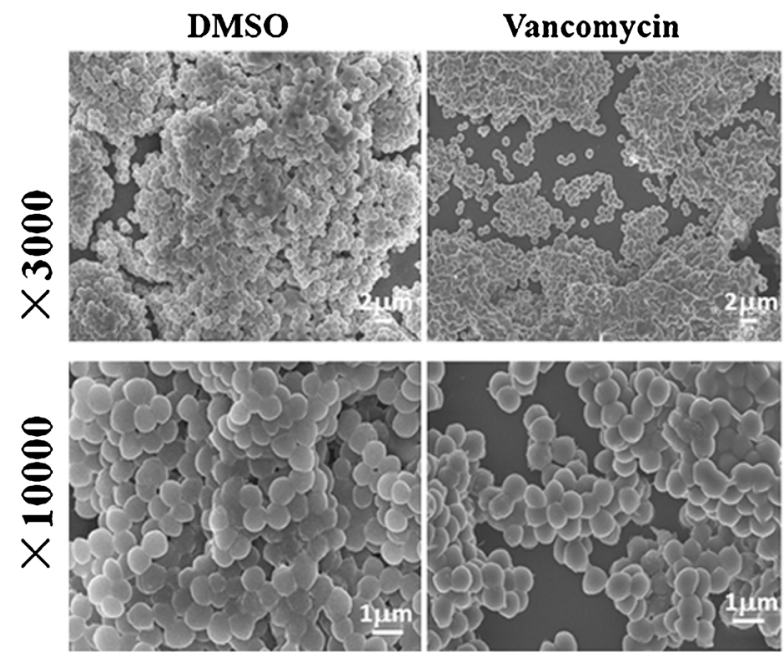

Fig. 3 SEM of biofilms treated with the derivatives $\mathrm{H} 2-74$ or $\mathrm{H} 2-81$. An overnight culture of $S$. epidermidis ATCC 35984 was inoculated into polystyrene 96-well plates and incubated for $6 \mathrm{~h}$. Then, DMSO,

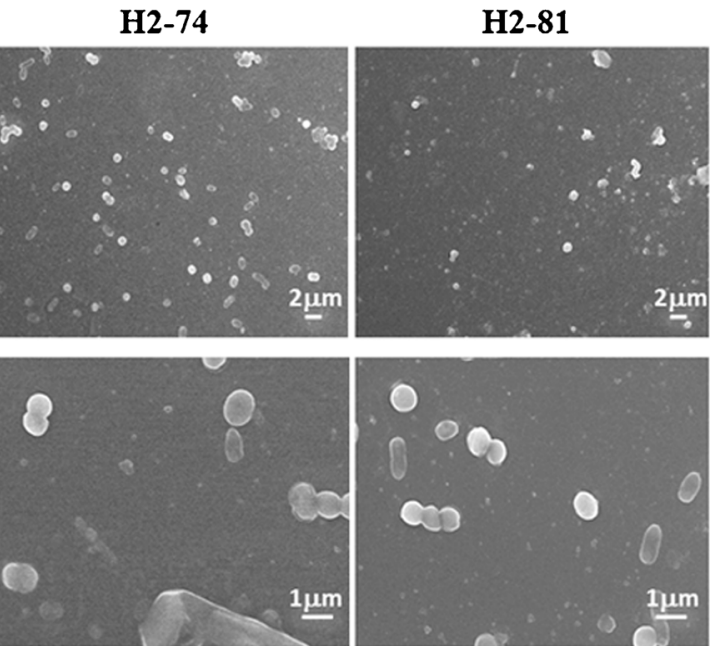

vancomycin $(128 \mathrm{mg} / \mathrm{l})$, or $4 \times \mathrm{MIC}$ of $\mathrm{H} 2-74$ and $\mathrm{H} 2-81$ was added into each well and incubated for $16 \mathrm{~h}$. The biofilm samples were fixed with gluteraldehyde and observed by SEM 

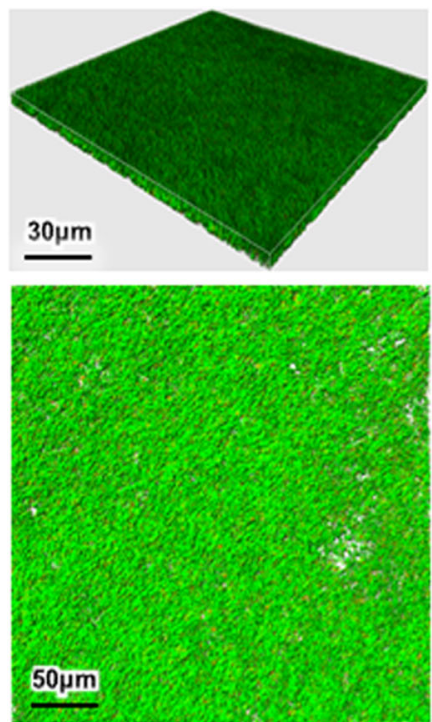

DMSO(93.5\%)
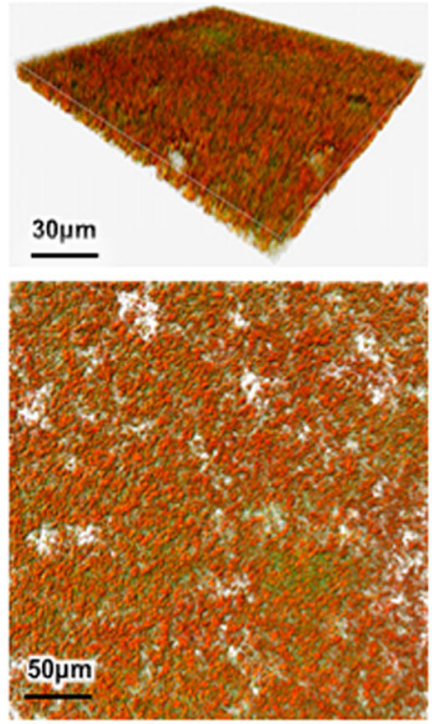

H2-57 (17.1\%)
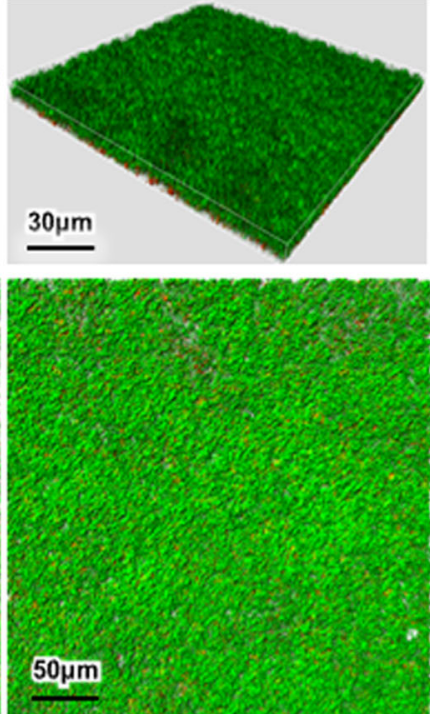

Vancomycin $(88.6 \%)$
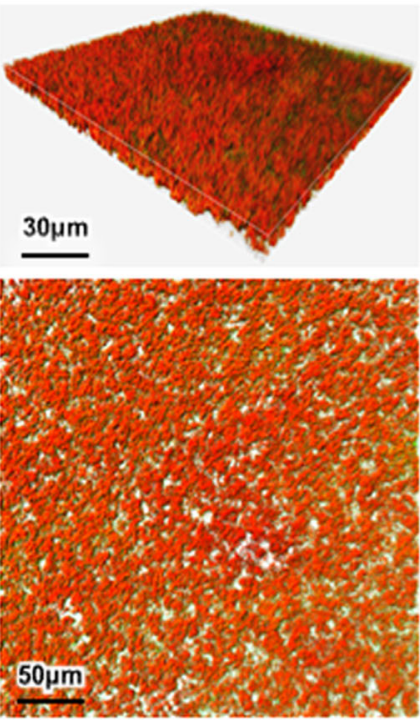

H2-60(14.0\%)
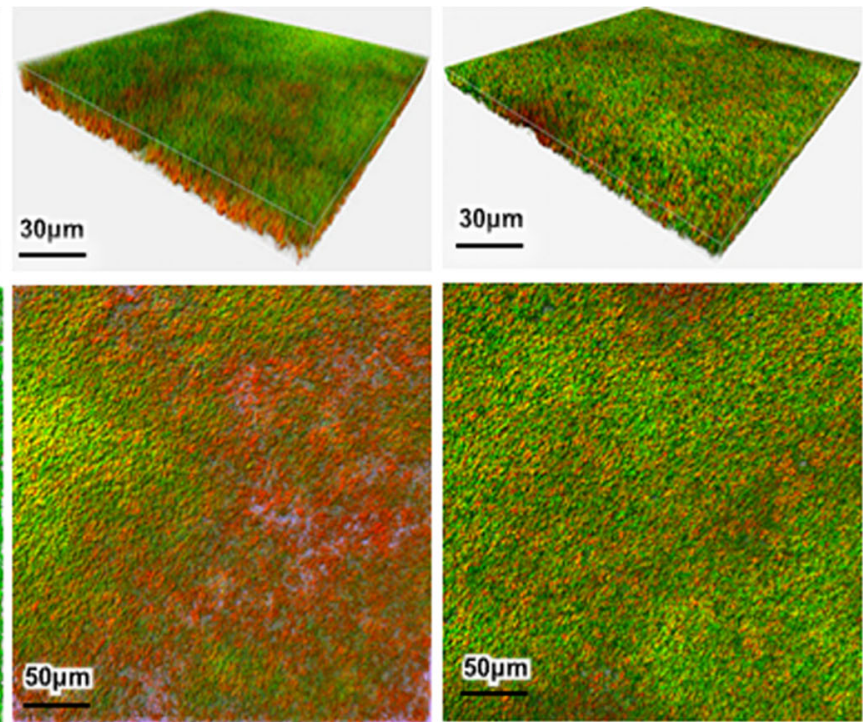

H2-38(42.3\%)
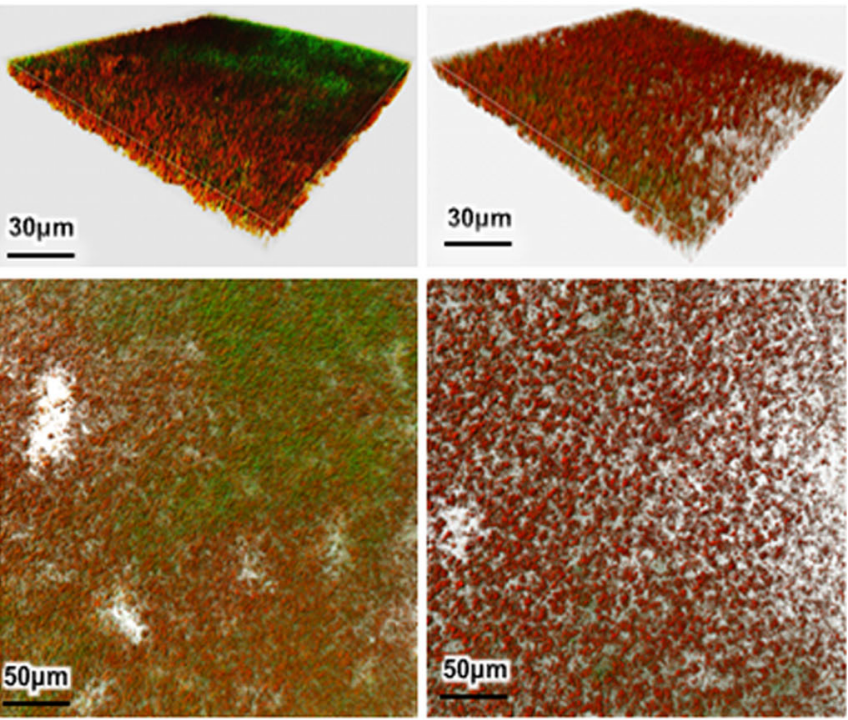

H2-74(32.5\%)

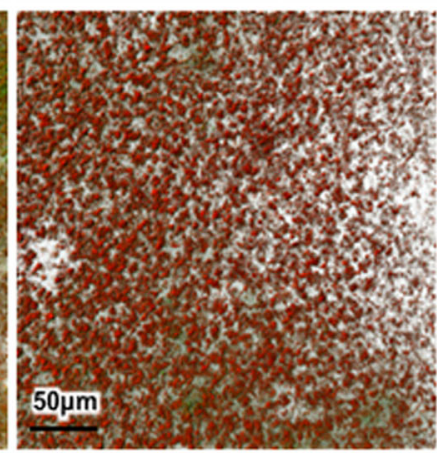

H2-81(12.3\%)

Fig. 4 Bactericidal effect of derivatives on mature biofilms of $S$. epidermidis observed by CLSM. Overnight cultures of $S$. epidermidis ATCC 35984 were inoculated into FluoroDishes and incubated at $37^{\circ} \mathrm{C}$ for $24 \mathrm{~h}$, and then the biofilms were treated with derivatives at concentrations of $4 \times$ MIC for another $16 \mathrm{~h}$. The biofilms were visualized by CLSM with Live/Dead BacLight viability staining (SYTO9/PI). Cells

\section{Discussion}

Many new compounds with antibacterial activities have been discovered through structure-activity studies and library screening using the core scaffold of potential targets. These include inhibitors targeting the kinase activities of $\mathrm{YycF}$ and YycG (Watanabe et al. 2003). The YycFG TCS or its orthologs (also referred as WalRK) (Dubrac et al. 2007) have been found in most low $\mathrm{G}+\mathrm{C}$ gram-positive bacteria, including many important pathogens. They play important roles in

stained with green fluorescence are viable and with red fluorescence are dead. The images of three-dimensional biofilm structure were created by IMARIS 7.0.0 software. The percentages of green bacteria in total bacteria were calculated by ImageJ using the intensity of green fluorescence divided by that of total fluorescence

regulating bacterial murein and exopolysaccharide biosynthesis, biofilm formation, cell division, and virulence factor expression (Bisicchia et al. 2007; Dubrac and Msadek 2004; Ng et al. 2003; Winkler and Hoch 2008). Inhibitors against YycG or $\mathrm{YycF}$ are bactericidal for gram-positive pathogens (Okada et al. 2010). It has been reported that the inhibitors walkmycin $\mathrm{B}$ that targets $\mathrm{YycG}$ and walrycin $\mathrm{A} / \mathrm{B}$ that targets $\mathrm{YycF}$ are effective against Bacillus subtilis and S. aureus at low MICs, though efficacy against biofilms has not been described (Okada et al. 2010; Watanabe et al. 2003). 


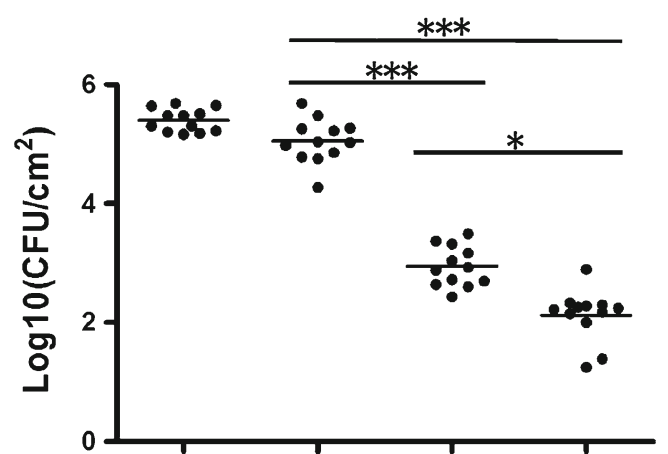

Fig. 5 The viable bacteria recovered from the implanted disks in rabbit subcutaneous $S$. epidermidis infection model. The effects of $\mathrm{H} 2-74$ and H2-81 on 24-h biofilms of S. epidermidis ATCC 35984 were tested in a rabbit subcutaneous $S$. epidermidis infection model. Biofilm-covered polyethylene disks were implanted in subcutaneous cavities and exposed to $\mathrm{H} 2-74(6.3 \mu \mathrm{M}, 4 \times \mathrm{MIC})$ or $\mathrm{H} 2-81(6.3 \mu \mathrm{M}, 4 \times \mathrm{MIC})$ by three intracavity injections at $24-\mathrm{h}$ intervals. Vancomycin $(128 \mathrm{mg} / \mathrm{l})$ and $0.1 \%$ DMSO were administered as controls. Twenty-four hours after the last treatment, the implants were taken out and viable bacteria on the disks were determined by CFU counting. Y-axis represents the number of S. epidermidis CFU; each dot in the figure represents the count of viable cells from one disk. Data were analyzed by ANOVA with Bonferroni's multiple comparison test; ${ }^{*} p<0.05$ and $* * * p<0.001(n=12)$

In previous studies, we have found two leading compounds (compound 2 and compound 5) that target $\mathrm{YycG}$ and have antibiofilm activities against S. epidermidis (Qin et al. 2006). To improve the antibacterial activities of compound 2, we designed and synthesized a series of derivatives, keeping the thiazolidione core structure intact (Huang et al. 2012; Pan et al. 2010). Here, the anti-staphylococcal activities of 56 of the newly synthesized derivatives were tested, and six showed higher antibacterial activities (MIC ranged from 1.5 to $6.3 \mu \mathrm{M})$ than the leading compound $2(\mathrm{MIC}=25 \mu \mathrm{M})$ and $\mathrm{H} 2-28(\mathrm{MIC}=3.1 \mu \mathrm{M})$ than previously reported (Huang et al. 2012). These six new derivatives exhibited antimicrobial activities against both MSRE and MSRA clinical isolates. All of them have halogen substituents $(\mathrm{F}$ or $\mathrm{Cl}$ ) on phenyl rings of the thiazolidine core structure, indicating that introducing halogen elements maintained or improved the potent antibacterial activity of compound 2 .

The six derivatives, especially $\mathrm{H} 2-57, \mathrm{H} 2-74$, and $\mathrm{H} 2-81$, were bactericidal against $S$. epidermidis cells in mature biofilms, and their antibiofilm activities have been improved compared to that of compound 2 and the derivatives studied previously (H2-10, H2-12, H2-20, H2-27, H2-28, H2-29) (Huang et al. 2012). At the highest concentration of the derivatives used in this study $(200 \mu \mathrm{M})$, no cytotoxicity or hemolytic activities were observed. Furthermore, in the rabbit subcutaneous $S$. epidermidis biofilm infection model, the tested derivatives (H2-74 and H2-81) reduced bacterial viability, indicating their potential efficacy against clinical biofilm infection in vivo.

Although H2-74 and H2-81 showed the same bacteriostatic activities $(\mathrm{MIC}=1.5 \mu \mathrm{M})$, they had different bactericidal efficacy; when $S$. epidermidis planktonic cells were treated with $\mathrm{H} 2-81$ at the concentration of $4 \times$ MIC for $10 \mathrm{~h}$ only, $\sim 10 \mathrm{CFU}$ remained, while for $\mathrm{H} 2-74,3.2 \times 10^{2} \mathrm{CFU}$ were detected. Consistent with this, the $\mathrm{IC}_{50}$ of $\mathrm{H} 2-74(71.2 \mu \mathrm{M})$ was higher than that of H2-81 $(24.2 \mu \mathrm{M})$. Comparison of the two derivatives' structures shows that H2-74 contains a 4phenoxy-acid fragment while H2-81 bears a 3-(5-thiophene2-yl) benzoic acid fragment. The incorporation of a 2phenylfuran moiety could enhance antibacterial activity of compounds (Ashok et al. 2007), and furan rings had been introduced into the derivatives $\mathrm{H} 2-38, \mathrm{H} 2-39$, and $\mathrm{H} 2-57$, which also displayed potent antibacterial activities and inhibitory effect on the phosphorylation of the $\mathrm{YycG}^{\prime}$ protein. The furan moiety was replaced with thiophene based on bioisosterism in H2-60 and H2-81, and both structures showed similar antibacterial activity and inhibitory effect on the phosphorylation of the $\mathrm{YycG}^{\prime}$ protein. This indicates that incorporation of a furan or thiophene ring and introducing halogen elements in the appropriate position may improve the antibacterial activities of the derivatives.

Combination antimicrobial therapy is widely used to take advantage of different mechanisms of action. It may potentiate the effect of individual antimicrobial agents by synergic action (Bijnsdorp et al. 2011; Cokol et al. 2011). The glycopeptide antibiotics, such as vancomycin, can bind the peptidoglycan side chains in the cell wall and prevent cross-linking during cell wall synthesis. Vancomycin has been considered to be one of the most reliable therapeutic agents against staphylococcal infections, but it is unable to clear biofilms even at high concentration (128 mg/l) (Climo et al. 1999; Darouiche et al. 1994; Tenover et al. 2001). Cefazolin has been used to treat various bacterial infections worldwide since the 1970s, and it can competitively inhibit the transpeptidases known as penicillin-binding proteins (PBPs) in the final transpeptidation step of the synthesis of peptidoglycan. YycGF also plays an important role in the synthesis of peptidoglycan in B. subtilis and S. aureus (Bisicchia et al. 2007; Dubrac and Msadek 2004). In a preliminary study, we assessed the effects of the combined application of the derivatives with vancomycin and cefazolin against $S$. epidermidis ATCC 35984 according to the method of Odds (2003) (Cottagnoud et al. 2003). A synergistic effect on S. epidermidis was observed when H2-81 was combined with vancomycin or cefazolin. No antagonism was observed between the derivatives and vancomycin or cefazolin (Table S1). These observations suggested that the derivatives may be used either alone or in association with other antibiotics. The potential synergistic effects in drug combinations warrant further investigation with clinical staphylococcal strains and multiresistant isolates.

Biofilms are highly resistant to clearance by most antimicrobial therapies because of the complicated multicellular architecture (Kittinger et al. 2011). The subcutaneous foreign body infection animal models are established for studying the 
effect of remedies on medical device-related biofilms, including mice, rat, and rabbit models (Coenye and Nelis 2010). Compared with other subcutaneous foreign body biofilm infection models, rabbit models are easy to manipulate and can be treated with different derivatives at the same time to reduce individual differences. In the present study, we used the rabbit subcutaneous S. epidermis biofilm infection models to evaluate the antibiofilm efficacy of the derivatives in vivo. After the treatment of H2-74 and H2-81 locally, CFUs in the biofilms were significantly reduced compared with untreated controls. This is in concordance with antibiofilm efficacy in vitro.

In summary, the bactericidal and antibiofilm activities of the six newly designed derivatives of $\mathrm{YycG}$ inhibitors are improved compared to prototype compound 2. However, the antimicrobial efficacy of derivatives should be further improved by additional modification of the compound structures. Studies of the toxicity in vivo and of the preclinical druggability of the derivatives will also be needed before there might be clinical application against biofilm-associated infections and multidrug-resistant bacterial infections.

Acknowledgments This work was supported by the National Science and Technology Major Project of China (2012ZX 09301002-001-005, 2012ZX10004401, and 2012ZX10003008-010), the National Natural Science Foundation of China $(81101214,21072095,21242003$, 81271594, and 81271791), and the High-Tech Research and Development Program of China (2010DFA32100). We would like to express our thanks to Dr. Douglas Lowrie who spent his precious time to carefully read the manuscript and to correct the language of the article.

Open Access This article is distributed under the terms of the Creative Commons Attribution License which permits any use, distribution, and reproduction in any medium, provided the original author(s) and the source are credited.

\section{References}

Aendekerk S, Diggle SP, Song Z, Hoiby N, Cornelis P, Williams P, Camara $M$ (2005) The MexGHI-OpmD multidrug efflux pump controls growth, antibiotic susceptibility and virulence in Pseudomonas aeruginosa via 4-quinolone-dependent cell-to-cell communication. Microbiology 151(Pt 4):1113-1125. doi:10.1099/mic.0.27631-0

Ashok M, Holla BS, Kumari NS (2007) Convenient one pot synthesis of some novel derivatives of thiazolo[2,3-b]dihydropyrimidinone possessing 4-methylthiophenyl moiety and evaluation of their antibacterial and antifungal activities. Eur J Med Chem 42(3):380-385. doi:10.1016/j.ejmech.2006.09.003

Barrett JF, Hoch JA (1998) Two-component signal transduction as a target for microbial anti-infective therapy. Antimicrob Agents Chemother 42(7): 1529-1536

Bijnsdorp IV, Giovannetti E, Peters GJ (2011) Analysis of drug interactions. Methods Mol Biol 731:421-434. doi:10.1007/978-1-61779-080-5_34

Bisicchia P, Noone D, Lioliou E, Howell A, Quigley S, Jensen T, Jarmer H, Devine KM (2007) The essential YycFG two-component system controls cell wall metabolism in Bacillus subtilis. Mol Microbiol 65(1):180-200. doi:10.1111/j.1365-2958.2007.05782.x

Ceri H, Olson ME, Stremick C, Read RR, Morck D, Buret A (1999) The Calgary Biofilm Device: new technology for rapid determination of antibiotic susceptibilities of bacterial biofilms. J Clin Microbiol 37(6):1771-1776

Climo MW, Patron RL, Archer GL (1999) Combinations of vancomycin and beta-lactams are synergistic against staphylococci with reduced susceptibilities to vancomycin. Antimicrob Agents Chemother 43(7):1747-1753

Coenye T, Nelis HJ (2010) In vitro and in vivo model systems to study microbial biofilm formation. J Microbiol Methods 83(2):89-105. doi:10.1016/j.mimet.2010.08.018

Cokol M, Chua HN, Tasan M, Mutlu B, Weinstein ZB, Suzuki Y, Nergiz ME, Costanzo M, Baryshnikova A, Giaever G, Nislow C, Myers CL, Andrews BJ, Boone C, Roth FP (2011) Systematic exploration of synergistic drug pairs. Mol Syst Biol 7:544. doi:10.1038/msb.2011.71

Cottagnoud P, Cottagnoud M, Tauber MG (2003) Vancomycin acts synergistically with gentamicin against penicillin-resistant pneumococci by increasing the intracellular penetration of gentamicin. Antimicrob Agents Chemother 47(1):144-147

D’Arezzo S, Lanini S, Puro V, Ippolito G, Visca P (2012) High-level tolerance to triclosan may play a role in Pseudomonas aeruginosa antibiotic resistance in immunocompromised hosts: evidence from outbreak investigation. BMC Res Notes 5:43. doi:10.1186/17560500-5-43

Dan Zhao HL, Zheng L, He G, Di Q, Han S (2013) Synthesis of novel 4thiazolidione derivatives as antibacterial agents against drugresistant Staphylococcus epidermidis. Med Chem Res 3743-3750

Darouiche RO, Dhir A, Miller AJ, Landon GC, Raad II, Musher DM (1994) Vancomycin penetration into biofilm covering infected prostheses and effect on bacteria. J Infect Dis 170(3):720-723

Donlan RM, Costerton JW (2002) Biofilms: survival mechanisms of clinically relevant microorganisms. Clin Microbiol Rev 15(2): 167-193

Dubrac S, Msadek T (2004) Identification of genes controlled by the essential YycG/YycF two-component system of Staphylococcus aureus. J Bacteriol 186(4):1175-1181

Dubrac S, Boneca IG, Poupel O, Msadek T (2007) New insights into the WalK/WalR (YycG/YycF) essential signal transduction pathway reveal a major role in controlling cell wall metabolism and biofilm formation in Staphylococcus aureus. J Bacteriol 189(22):82578269. doi:10.1128/JB.00645-07

Falsetta ML, Klein MI, Lemos JA, Silva BB, Agidi S, Scott-Anne KK, Koo H (2012) Novel antibiofilm chemotherapy targets exopolysaccharide synthesis and stress tolerance in Streptococcus mutans to modulate virulence expression in vivo. Antimicrob Agents Chemother 56(12):6201-6211. doi:10.1128/AAC.01381-12

Fukushima T, Furihata I, Emmins R, Daniel RA, Hoch JA, Szurmant H (2011) A role for the essential YycG sensor histidine kinase in sensing cell division. Mol Microbiol 79(2):503-522. doi:10.1111/j. 1365-2958.2010.07464.x

Giacometti A, Cirioni O, Schimizzi AM, Del Prete MS, Barchiesi F, D'Errico MM, Petrelli E, Scalise G (2000) Epidemiology and microbiology of surgical wound infections. J Clin Microbiol 38(2): 918-922

He N, Hu J, Liu H, Zhu T, Huang B, Wang X, Wu Y, Wang W, Qu D (2011) Enhancement of vancomycin activity against biofilms by using ultrasound-targeted microbubble destruction. Antimicrob Agents Chemother 55(11):5331-5337. doi:10.1128/AAC.00542-11

Huang RZ, Zheng LK, Liu HY, Pan B, Hu J, Zhu T, Wang W, Jiang DB, Wu Y, Wu YC, Han SQ, Qu D (2012) Thiazolidione derivatives targeting the histidine kinase YycG are effective against both planktonic and biofilm-associated Staphylococcus epidermidis. Acta Pharmacol Sin 33(3):418-425. doi:10.1038/aps.2011.166

Kiedrowski MR, Horswill AR (2011) New approaches for treating staphylococcal biofilm infections. Ann N Y Acad Sci 1241:104-121. doi: $10.1111 / \mathrm{j} .1749-6632.2011 .06281 . \mathrm{x}$

Kiran GS, Sabarathnam B, Selvin J (2010) Biofilm disruption potential of a glycolipid biosurfactant from marine Brevibacterium casei. FEMS 
Immunol Med Microbiol 59(3):432-438. doi:10.1111/j.1574-695X. 2010.00698.x

Kittinger C, Marth E, Windhager R, Weinberg AM, Zarfel G, Baumert R, Felisch S, Kuehn KD (2011) Antimicrobial activity of gentamicin palmitate against high concentrations of Staphylococcus aureus. J Mater Sci Mater Med 22(6):1447-1453. doi:10.1007/s10856-0114333-4

Knobloch JK, Bartscht K, Sabottke A, Rohde H, Feucht HH, Mack D (2001) Biofilm formation by Staphylococcus epidermidis depends on functional RsbU, an activator of the sigB operon: differential activation mechanisms due to ethanol and salt stress. J Bacteriol 183(8):2624-2633. doi:10.1128/JB.183.8.2624-2633.2001

Lee YS, Kang OH, Choi JG, Oh YC, Chae HS, Kim JH, Park H, Sohn DH, Wang ZT, Kwon DY (2008) Synergistic effects of the combination of galangin with gentamicin against methicillin-resistant Staphylococcus aureus. J Microbiol 46(3):283-288. doi:10.1007/ s12275-008-0012-7

Mah TF, O'Toole GA (2001) Mechanisms of biofilm resistance to antimicrobial agents. Trends Microbiol 9(1):34-39

Miyoshi S, Sasahara K, Akamatsu S, Rahman MM, Katsu T, Tomochika K, Shinoda S (1997) Purification and characterization of a hemolysin produced by Vibrio mimicus. Infect Immun 65(5):1830-1835

Ng WL, Robertson GT, Kazmierczak KM, Zhao J, Gilmour R, Winkler ME (2003) Constitutive expression of PcsB suppresses the requirement for the essential VicR (YycF) response regulator in Streptococcus pneumoniae R6. Mol Microbiol 50(5):1647-1663

O'Gara JP, Humphreys H (2001) Staphylococcus epidermidis biofilms: importance and implications. J Med Microbiol 50(7):582-587

Odds FC (2003) Synergy, antagonism, and what the chequerboard puts between them. J Antimicrob Chemother 52(1):1. doi:10.1093/jac/ dkg301

Okada A, Igarashi M, Okajima T, Kinoshita N, Umekita M, Sawa R, Inoue $\mathrm{K}$, Watanabe $\mathrm{T}$, Doi A, Martin A, Quinn J, Nishimura Y, Utsumi R (2010) Walkmycin B targets WalK (YycG), a histidine kinase essential for bacterial cell growth. J Antibiot (Tokyo) 63(2): 89-94. doi:10.1038/ja.2009.128

Otto M (2012a) Molecular basis of Staphylococcus epidermidis infections. Semin Immunopathol 34(2):201-214. doi:10.1007/s00281011-0296-2

Otto M (2012b) Staphylococcal infections: mechanisms of biofilm maturation and detachment as critical determinants of pathogenicity. Annu Rev Med. doi:10.1146/annurev-med- 042711-140023

Pan B, Huang RZ, Han SQ, Qu D, Zhu ML, Wei P, Ying HJ (2010) Design, synthesis, and antibiofilm activity of 2-arylimino-3-arylthiazolidine-4-ones. Bioorg Med Chem Lett 20(8):2461-2464. doi: 10.1016/j.bmcl.2010.03.013

Parra-Ruiz J, Bravo-Molina A, Pena-Monje A, Hernandez-Quero J (2012) Activity of linezolid and high-dose daptomycin, alone or in combination, in an in vitro model of Staphylococcus aureus biofilm. J Antimicrob Chemother 67(11):2682-2685. doi:10.1093/jac/ dks272
Qin Z, Zhang J, Xu B, Chen L, Wu Y, Yang X, Shen X, Molin S, Danchin A, Jiang H, Qu D (2006) Structure-based discovery of inhibitors of the YycG histidine kinase: new chemical leads to combat Staphylococcus epidermidis infections. BMC Microbiol 6:96. doi: 10.1186/1471-2180-6-96

Roper DI, Huyton T, Vagin A, Dodson G (2000) The molecular basis of vancomycin resistance in clinically relevant enterococci: crystal structure of D-alanyl-D-lactate ligase (VanA). Proc Natl Acad Sci U S A 97(16):8921-8925. doi:10.1073/pnas.150116497

Spoering AL, Lewis K (2001) Biofilms and planktonic cells of Pseudomonas aeruginosa have similar resistance to killing by antimicrobials. J Bacteriol 183(23):6746-6751. doi:10.1128/JB.183.23. 6746-6751.2001

Stepanovic S, Vukovic D, Hola V, Di Bonaventura G, Djukic S, Cirkovic I, Ruzicka F (2007) Quantification of biofilm in microtiter plates: overview of testing conditions and practical recommendations for assessment of biofilm production by staphylococci. APMIS 115(8): 891-899. doi:10.1111/j.1600-0463.2007.apm 630.x

Szurmant H, Nelson K, Kim EJ, Perego M, Hoch JA (2005) YycH regulates the activity of the essential YycFG two-component system in Bacillus subtilis. J Bacteriol 187(15):5419-5426. doi:10.1128/JB. 187.15.5419-5426.2005

Tenover FC, Biddle JW, Lancaster MV (2001) Increasing resistance to vancomycin and other glycopeptides in Staphylococcus aureus. Emerg Infect Dis 7(2):327-332. doi:10.3201/eid0702.700327

Turck M, Bierbaum G (2012) Purification and activity testing of the fulllength YycFGHI proteins of Staphylococcus aureus. PLoS One 7(1):e30403. doi:10.1371/journal.pone.0030403

Turnidge J, Bordash G (2007) Statistical methods for establishing quality control ranges for antibacterial agents in Clinical and Laboratory Standards Institute susceptibility testing. Antimicrob Agents Chemother 51(7):2483-2488. doi:10.1128/AAC.01457-06

Walters MC 3rd, Roe F, Bugnicourt A, Franklin MJ, Stewart PS (2003) Contributions of antibiotic penetration, oxygen limitation, and low metabolic activity to tolerance of Pseudomonas aeruginosa biofilms to ciprofloxacin and tobramycin. Antimicrob Agents Chemother 47(1):317-323

Watanabe T, Hashimoto Y, Yamamoto K, Hirao K, Ishihama A, Hino M, Utsumi R (2003) Isolation and characterization of inhibitors of the essential histidine kinase, YycG in Bacillus subtilis and Staphylococcus aureus. J Antibiot (Tokyo) 56(12):1045-1052

West AH, Stock AM (2001) Histidine kinases and response regulator proteins in two-component signaling systems. Trends Biochem Sci 26(6):369-376

Winkler ME, Hoch JA (2008) Essentiality, bypass, and targeting of the YycFG (VicRK) two-component regulatory system in grampositive bacteria. J Bacteriol 190(8):2645-2648. doi:10.1128/JB. 01682-07

Yarwood JM, Bartels DJ, Volper EM, Greenberg EP (2004) Quorum sensing in Staphylococcus aureus biofilms. J Bacteriol 186(6): $1838-1850$ 